Article

\title{
Polyimide-Coated Glass Microfiber as Polysulfide Perm-Selective Separator for High-Performance Lithium-Sulphur Batteries
}

\author{
Mi-Jin Kim ${ }^{1}{ }^{\circledR}$, Kwansoo Yang ${ }^{2}$, Hui-Ju Kang ${ }^{1}{ }^{\oplus}$, Hyun Jin Hwang ${ }^{1}{ }^{\circledR}$, Jong Chan Won ${ }^{2,3}$, \\ Yun Ho Kim 2,3,* and Young-Si Jun 1,*(D) \\ 1 School of Chemical Engineering, Chonnam National University, 77 Yongbongro, Buk-gu, Gwangju 61186, \\ Korea; mijinkim999@gmail.com (M.-J.K.); gmlwn120@gmail.com (H.-J.K.); wgguswls@gmail.com (H.J.H.) \\ 2 Advanced Materials Division, Korea Research Institute of Chemical Technology (KRICT), 141 Gajeongro, \\ Yuseong-gu, Daejeon 34114, Korea; sky215@krict.re.kr (K.Y.); jcwon@krict.re.kr (J.C.W.) \\ 3 Advanced materials and chemical engineering, KRICT School, University of Science and Technology, \\ Daejeon 34113, Korea \\ * Correspondence: yunho@krict.re.kr (Y.H.K.); ysjun@jnu.ac.kr (Y.-S.J.); \\ Tel.: +82-42-860-7274 (Y.H.K.); +82-62-530-1812 (Y.-S.J.)
}

Received: 22 October 2019; Accepted: 9 November 2019; Published: 13 November 2019

\begin{abstract}
Although numerous research efforts have been made for the last two decades, the chronic problems of lithium-sulphur batteries (LSBs), i.e., polysulfide shuttling of active sulphur material and surface passivation of the lithium metal anode, still impede their practical application. In order to mitigate these issues, we utilized polyimide functionalized glass microfibers (PI-GF) as a functional separator. The water-soluble precursor enabled the formation of a homogenous thin coating on the surface of the glass microfiber (GF) membrane with the potential to scale and fine-tune: the PI-GF was prepared by simple dipping of commercial GF into an aqueous solution of poly(amic acid), (PAA), followed by thermal imidization. We found that a tiny amount of polyimide (PI) of $0.5 \mathrm{wt} . \%$ is more than enough to endow the GF separator with useful capabilities, both retarding polysulfide migration. Combined with a free-standing microporous carbon cloth-sulphur composite cathode, the PI-GF-based LSB cell exhibits a stable cycling over 120 cycles at a current density of $1 \mathrm{~mA} / \mathrm{cm}^{2}$ and an areal sulphur loading of $2 \mathrm{mgS} / \mathrm{cm}^{2}$ with only a marginal capacity loss of $0.099 \% /$ cycle. This corresponds to an improvement in cycle stability by $200 \%$, specific capacity by $16.4 \%$, and capacity loss per cycle by $45 \%$ as compared to those of the cell without PI coating. Our study revealed that a simple but synergistic combination of porous carbon supporting material and functional separator enabled us to achieve high-performance LSBs, but could also pave the way for the development of practical LSBs using the commercially viable method without using complicated synthesis or harmful and expensive chemicals.
\end{abstract}

Keywords: lithium-sulphur battery; polysulfide shuttling; separator; glass fibers; polyimide

\section{Introduction}

Ever-growing demand on energy for electricity and transportation and abrupt climate change increases energy security and environmental concerns. Since energy accounts for about $60 \%$ of anthropogenic $\mathrm{CO}_{2}$ emission, urgent action to decarbonize the energy sector is needed [1]. In order to keep the average temperature rise well below $2{ }^{\circ} \mathrm{C}$ above the pre-industrial level, the net cumulative $\mathrm{CO}_{2}$ emission must be lowered from 1.5 to around 1 trillion tonnes [2]. This implies that energy dependence on fossil fuel combustion must immediately be lessened more than $80 \%$. It is envisioned that renewable energies (REs) like solar and wind will achieve the target reduction of $\mathrm{CO}_{2}$ emissions. 
Indeed, a transition from fossil fuel to REs is currently well under way. For example, global energy investment on REs was increased by $17 \%$ to $\sim 270$ billion in 2014 . The capacity generation from REs was $\sim 100,000 \mathrm{MW}$ around the globe in 2014, corresponding to $9.1 \%$ of the world's electricity [3].

The successful penetration of the REs into the energy sector requires their implementation with energy storage systems (ESSs) due to intermittency and location issues. Accordingly, we demand a battery technology that is safe, inexpensive, and long-lasting without performance loss as well as featuring high energy/power density [4]. Despite great success in portable electronics, penetration of the current state-of-the-art battery technology, i.e., lithium-ion batteries (LIBs), into this market is hampered by several limitations. They require further cost reduction $(<\$ 100 / \mathrm{kWh})$ especially for cathode material based on $\mathrm{Co}, \mathrm{Ni}$, and $\mathrm{Mn}$. In addition, they are not only reaching their energy density limit $(\sim 240 \mathrm{Wh} / \mathrm{kg})$, but also have critical safety concerns of the thermal runaway [5,6]. Lithium-sulphur batteries (LSBs) with a theoretical energy density of $2600 \mathrm{Wh} / \mathrm{kg}$ and generating thermally-stable $\mathrm{Li}_{2} \mathrm{~S}$ (m.p. $>900{ }^{\circ} \mathrm{C}$ ) have been considered a promising alternative to LIBs for over two decades $[7,8]$. Sulphur has a theoretical specific capacity of $1672 \mathrm{mAh} / \mathrm{g}$ and is inexpensive $(\$ 0.02 / \mathrm{g})$, earth-abundant, and environmentally friendly. What is more, a major source of its elemental form is oil refineries in which sulphur is a by-product, and refinery sulphur production is projected to increase with the US and Europe tightening environmental regulations and the crude oil from the underground becoming heavier and thus more sulphurous [9]. In general, LSBs consist of a metallic lithium anode and a sulphur cathode. The active material sulphur or related species undergoes multi-step reduction/oxidation during discharge/charge procedures based on the redox couple: $16 \mathrm{Li}+\mathrm{S}_{8}<->$ $8 \mathrm{Li}_{2} \mathrm{~S}$ [7]. The reaction-based mechanism, generating two electrons per one lightweight sulphur atom, endows LSBs with a much higher specific capacity and energy density as compared to those of the intercalation-based LIBs, whose active material often provides a single electron generation and contains a high portion of dead-mass components [10].

Despite all of these advantages, the practical application of LSBs is yet impeded by several technical challenges, including: (1) inherently low electronic conductivity of charge/discharge products, i.e., sulphur and $\mathrm{Li}_{2} \mathrm{~S}$; (2) active material loss by dissolution of lithium polysulfide $\left(\mathrm{Li}_{2} \mathrm{~S}_{n}, n=4-8\right)$ formed by the reaction between sulphur and lithium into electrolyte; and (3) the subsequent passivation of the lithium metal anode by the soluble polysulfides transferred from the cathode [11]. In order to mitigate these issues, much research effort has, so far, been given to the development of conductive additive or porous supporting material with the dimensions on a nanometer scale to improve the electronic/ionic conductivity of sulphur, organic/polymer/solid electrolytes with low solubility for polysulfides to minimize their dissolution from the cathode, additives therein to protect the surface of the lithium metal anode from $\mathrm{Li}_{2} \mathrm{~S}$ passivation, anode active materials which hardly react with polysulfides, etc. [12-20]. The implication of these researches is that it is almost impossible for one strategy to completely prevent the dissolution and subsequent shuttling of the polysulfides without loss in either cycle stability or sulphur utilization efficiency. For example, the well-designed carbon cathode entails high polysulfide dissolution after repeated cycles as well as the high utilization efficiency ( $>90 \%$ ) of sulphur close to the theoretical value. Also, the sulphur utilization in the presence of solid/polymer electrolyte or highly concentrated electrolyte gets lower than in the typical liquid electrolyte such as a mixture of 1,3-dioxolane and 1,2-dimethoxyethane (1:1, v/v), although these electrolytes retard the polysulfide dissolution to some extent. Polyolefin-based separators such as polypropylene (PP) and polyethylene (PE) are commonly used in LSBs and coated with various organic and inorganic materials, but they exhibit large thermal shrinkage at elevated temperatures and contain flammable components with the risk of ignition and flame in the case of overcharging or overheating [21,22]. Although a solid/polymer electrolyte which acts as a physical barrier for dissolved polysulfide have been widely investigated, degradation of electrochemical performance due to low ionic conductivity is inevitable in addition to the composite electrode suffering from high contact resistance at the electrode-electrolyte interface [23,24].

Almost all of the battery cell components must simultaneously be improved to cope with the challenges. Given that one strategy often counter-balances the advantage of the other, it is highly 
demanding to first investigate what might be a synergistic combination to achieve high-performance LSBs. To this end, we herein investigated the electrochemical behavior of porous carbon support toward sulphur in the presence of functional separator. It was our intention to create a synergy effect between the two different cell components in LSB cells where they were chosen to be either only electronically or ionically active such that they did not play overlapping roles. As such, the supporting material mainly improved the utilization of sulphur, while the separator retarded the polysulfide shuttling into the Li metal anode. Microporous carbon cloth (CC) was utilized as a sulphur supporting material without using additional conductive additives and polymer binders. The free-standing electrode infiltrated with polysulfides demonstrated a high performance of 1100 and $548 \mathrm{mAh} / \mathrm{g}$ corresponding to a sulphur utilization efficiency of 66 and 33\% at an areal sulphur loading of 2 and $6 \mathrm{mg} / \mathrm{cm}^{2}$, respectively, and 0.3C [25]. The commercial glass microfiber (GF) separator with an open porous structure, which otherwise exhibits high electrolyte permeability and is prone to polysulfide shuttling of polysulfides, was rendered polysulfide-affinitive by introducing a homogeneous thin coating of polyimide (PI) in which the imide groups, two $\mathrm{C}=\mathrm{O}$ groups linked to $\mathrm{N}$, were well known to have high affinity to polysulfides [26]. The electrochemical behavior of CC was compared with or without PI coating on GF at an electrolyte-to-sulphur (E/S) ratio of $>10$ by using the galvanostatic cycling with potential limit (GCPL) technique and electrochemical impedance spectroscopy (EIS). The resulting CC and polyimide functionalized glass microfibers (PI-GF) before and after GCPL cycling were also analyzed by SEM, EDS, and TGA.

\section{Materials and Methods}

\subsection{Materials}

Pyromellitic dianhydride (PMDA) and m-tolidine (m-TB) were purchased from Sunlight Chem Inc. (Changzhou, China) and used after drying in a vacuum oven at $60^{\circ} \mathrm{C}$ for $24 \mathrm{~h}$. N-Methyl-2-pyrrolidone (NMP, 99.8\%), and dimethylethanolamine (DMEA, 99.5\%) were purchased from Sigma-Aldrich (Darmstadt, Germany) and used as received without further purification. The glass microfiber (GF/C grade) membrane (Whatman lnc., Buckingham, UK) pore size: $1.2 \mu \mathrm{m}$, thickness: $260 \mu \mathrm{m}$ ) was used as received.

\subsection{Fabrication of PI Functionalized GF (PI-GF)}

Polyamic acid (PAA), the precursor solution of polyimide, was synthesized by using PMDA and $\mathrm{m}$-TB. First, $\mathrm{m}$-TB $(21.229 \mathrm{~g}, 0.1 \mathrm{~mol})$ was dissolved in NMP $(387.369 \mathrm{~g})$ at $0{ }^{\circ} \mathrm{C}$ under a nitrogen atmosphere. After complete dissolution, PMDA (21.812 $\mathrm{g}, 0.1 \mathrm{~mol})$ was gradually added. A viscous and yellow-colored PAA solution with a solid content of $\sim 10 \mathrm{wt} . \%$ was acquired after stirring for $24 \mathrm{~h}$. To obtain the PAA powder, the PAA solution was poured into deionized water, pulverized using a blender, filtered, and finally dried in a vacuum oven at $40{ }^{\circ} \mathrm{C}$ overnight. The aqueous PAA solution was then prepared by adding DMEA, the water dissolution agent, in water with a double amount of repeating units [27]. PI-GF was achieved by simply dipping the GF membrane into the as-prepared aqueous PAA solution. The immersed GF membrane was dried in a convection oven at $50^{\circ} \mathrm{C}$ for $1 \mathrm{~h}$ and then heated in a vacuum oven at $350^{\circ} \mathrm{C}$ for $2 \mathrm{~h}$ for thermal imidization.

\subsection{Preparation of Electrolytes and Catholytes}

The blank electrolyte is $1 \mathrm{M}$ lithium bis(trifluoromethanesulfonyl) imide (LiTFSI, 99.95\%, Sigma-Aldrich Inc., Darmstadt, Germany) dissolved in a 1:1 (v/v) mixture of 1,3-dioxolane (DOL, 99.8\%, Sigma-Aldrich Inc., Darmstadt, Germany) and 1,2-dimethoxyethane (DME, 99.5\%, Sigma-Aldrich Inc., Darmstadt, Germany) with 1 wt.\% lithium nitrate $\left(\mathrm{LiNO}_{3}, 99.99 \%\right.$, Sigma-Aldrich Inc., Darmstadt, Germany). To prepare the catholyte $\left(1 \mathrm{M} \mathrm{Li}_{2} \mathrm{~S}_{6}\right)$, the sulphur source, elemental sulphur (Sigma-Aldrich, $\geq 99.5 \%$ ) and $\mathrm{Li}_{2} \mathrm{~S}(99.9 \%$, Alfa-Aesar Inc., Seoul, Korea) were mixed in a blank electrolyte and heated at $50^{\circ} \mathrm{C}$ overnight. 


\subsection{Cell Assembly}

LSB cells were assembled using CR2032 coin cells in an Ar-filled glove box (below 0.1 ppm of $\mathrm{O}_{2}$ and $\mathrm{H}_{2} \mathrm{O}$ concentration). The catholyte was immersed into the commercial carbon cloth (CC, $\mathrm{CH} 900-20$, Kuractive, Kuraray Chemical Co., Ltd., Tokyo, Japan, $21 \mathrm{mg})$, to which the blank electrolyte (100 $\mu \mathrm{L})$ was added to make the total amount of electrolyte $200 \mu \mathrm{L}$. Then, the PI-GF (or GF) separator with a diameter of $19 \mathrm{~mm}$ and the Li metal anode with a diameter of $10 \mathrm{~mm}$ and a thickness of $0.75 \mathrm{~mm}$ were sequentially placed on top of the CC cathode.

\subsection{Characterization}

Thermogravimetric analysis (TGA-50) was conducted under nitrogen in the temperature range of 25 and $900{ }^{\circ} \mathrm{C}$ at a heating rate of $10^{\circ} \mathrm{C} / \mathrm{min}(\mathrm{CDFC})$. Fourier transform infrared (FT-IR) spectra were recorded with a JACSO FT-IR 4100 spectrometer (JACSO Inc., Tokyo, Japan). Field emission scanning electron microscopy (FE-SEM) images were obtained using HITACHI SU-70 (HITACHI Inc., Fukuoka, Japan) in the Korea Basic Science Institute (KBSI). The cycle stability was evaluated in the potential range between 1.8 and $2.6 \mathrm{~V}$ vs. $\mathrm{Li} / \mathrm{Li}^{+}$with a WBCS 3000 multi-channel cycler (WonATech, Seoul, Korea). Electrochemical impedance spectroscopy (EIS) was measured from $250 \mathrm{kHz}$ to $0.05 \mathrm{~Hz}$ by a VSP (Bio-Logic, Seyssinet-Pariset, France) potentiostat.

\section{Results and Discussion}

The GF membrane essentially consisted of borosilicate microfibers with a thickness in the range between 120 and $1900 \mathrm{~nm}$ (Figure 1a,b). Their random arrangement stacking with a thickness of 260 $\mu \mathrm{m}$ generated an open porous structure with a pore size of around $1.2 \mu \mathrm{m}$ which was about 28 times bigger than that $(0.043 \mu \mathrm{m})$ of the typical battery separator based on polypropylene (PP), i.e., Celgard 2400. In addition to the thermal stability as high as $550{ }^{\circ} \mathrm{C}$ (vs. $\sim 90^{\circ} \mathrm{C}$ for Celgard 2400 ), much higher than the thermal imidization temperature of PI, GF featured much higher electrolyte permeability than the Celgard membrane, which made it an ideal model separator (or substrate) to investigate the effect of the surface functional group, i.e., PI, on polysulfide shuttling without disturbance of physical trapping in the internal pore structure [26,28].

PI was in marked contrast to PP in that it had high thermal stability $\left(>500{ }^{\circ} \mathrm{C}\right)$ and wettability to electrolyte solvent. PI was introduced into GF by simple dipping into aqueous PAA solution and thermal curing as shown in Figure 1c. The PAA loaded on GF was fully converted into PI by heating at $350^{\circ} \mathrm{C}$ for $2 \mathrm{~h}$, after which the resulting PI-GF with a pale yellow color indicative of PI formation could be obtained (Figure 1g inset). The amount and depth of color of PI on GF could gradually be modified by dipping GF into aqueous PAA solution of different concentrations $(0.3,0.5$, and $1.0 \mathrm{wt} . \%)$. According to the concentration, these separators were referred to as PI-GF- $x(x=0.3,0.5$, and 1.0).

To enable the formation of the homogenous PI thin film on the hydrophilic surface of GF, we used water as a solvent for PAA instead of organic solvent to improve wettability and coating properties via hydrogen bonding $[29,30]$. In general, PAA has only limited solubility in water, while it dissolves well in polar aprotic organic solvents such as NMP, DMF, and DMAc [31]. Dissolution in water can be facilitated by reacting with the so-called water dissolution agents which are tertiary amines or alcohol amines such as dimethylethanolamine (DMEA) and trimethylamine. These amine compounds yield a salt complex with PAA via acid-amine reaction, substantially increasing solubility in water [27]. We found that the surface of GF indeed got wet faster with aqueous PAA solution than with organic PAA solution in NMP. As such, the PI coating resulting from aqueous solution was homogeneous and smooth, while that from the NMP solution was quite self-aggregated as shown in SEM images (Figure 1f). The surface morphology of GF remained almost intact before and after PI formation (PI-GF-0.5), meaning that the ultra-thin PI coating layer was homogeneously formed on the surface of GF thanks to the strong surface affinity of PAA to GF without affecting the chemical structure of silica. This holds true for PAA solution of $\sim 3$ wt. $\%$ (Figure 1d,e). 
FT-IR confirms the formation of PI on GF: the weak absorption bands of the imide ring, consisting of carbonyl carbons bound to nitrogen, newly appeared at 725 (deformation), $1363(\mathrm{C}-\mathrm{N})$, and 1722 $\left(\mathrm{C}=\mathrm{O}\right.$, sym.) $\mathrm{cm}^{-1}$ in the FT-IR spectrum of PI-GF-0.5 [32,33] (Figure 1g). The conversion of PAA into PI was successful as was revealed by the disappearance of the characteristic broad bands in the range from 3000 to $4000 \mathrm{~cm}^{-1}$ assigned to the $\mathrm{N}-\mathrm{H}$ and $\mathrm{O}-\mathrm{H}$ bonds of PAA. The other strong bands at 450, 787, and $1013 \mathrm{~cm}^{-1}$ were attributed to the bending vibration, symmetric stretching vibration, and asymmetric stretching vibration of $\mathrm{Si}-\mathrm{O}-\mathrm{Si}$, respectively, of silica retained in borosilicate microfibers [34,35]. The content of PI in PI-GF- $x$ was evaluated by heating PI-GF- $x$ samples in a muffle furnace at $550{ }^{\circ} \mathrm{C}$ for $4 \mathrm{~h}$ under air. As expected, mass loss increased with increasing $x$ from 0.3 to 1.0; PI-GF-0.3-1.0 samples showed mass losses of 2.0, 4.6, and $6.7 \mathrm{wt} . \%$, respectively, which corresponded to the PI content in PI-GF- $x$ (Figure $1 \mathrm{~h}$ inset). This supported our assumption that the PI loading on GF could simply be fine-tuned with the initial concentration of aqueous PAA solution in the range between 0.3 and $1 \mathrm{wt} . \%$. Note that the actual content of PI was probably lower by around $1 \mathrm{wt} . \%$ than the values obtained after the thermal decomposition in a muffle furnace; the borosilicate fibers also contributed to a mass loss of $\sim 1 \mathrm{wt} . \%$ as a result of the removal of surface hydroxy groups (Figure $1 \mathrm{~h}$ ). Also, it was found that PI-GF guaranteed thermal stability up to $300^{\circ} \mathrm{C}$ with a mass loss below $1 \mathrm{wt} . \%$, above which PI-GF- 0.5 showed an abrupt mass loss around $400{ }^{\circ} \mathrm{C}$ and continuous mass loss up to $700{ }^{\circ} \mathrm{C}$, partly as a result of thermal decomposition of PI (Figure $1 \mathrm{~h}$ ).
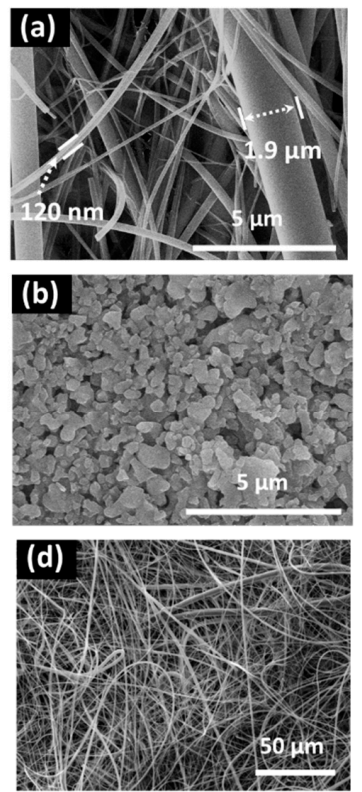

(c)

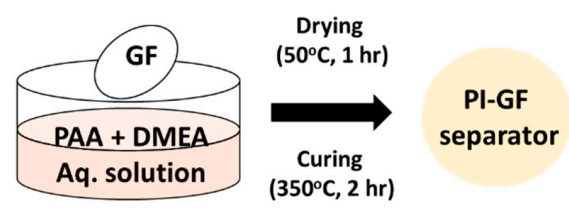

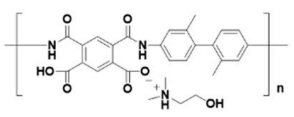

Poly(amic acid) salt

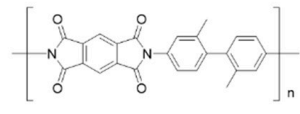

Polyimide
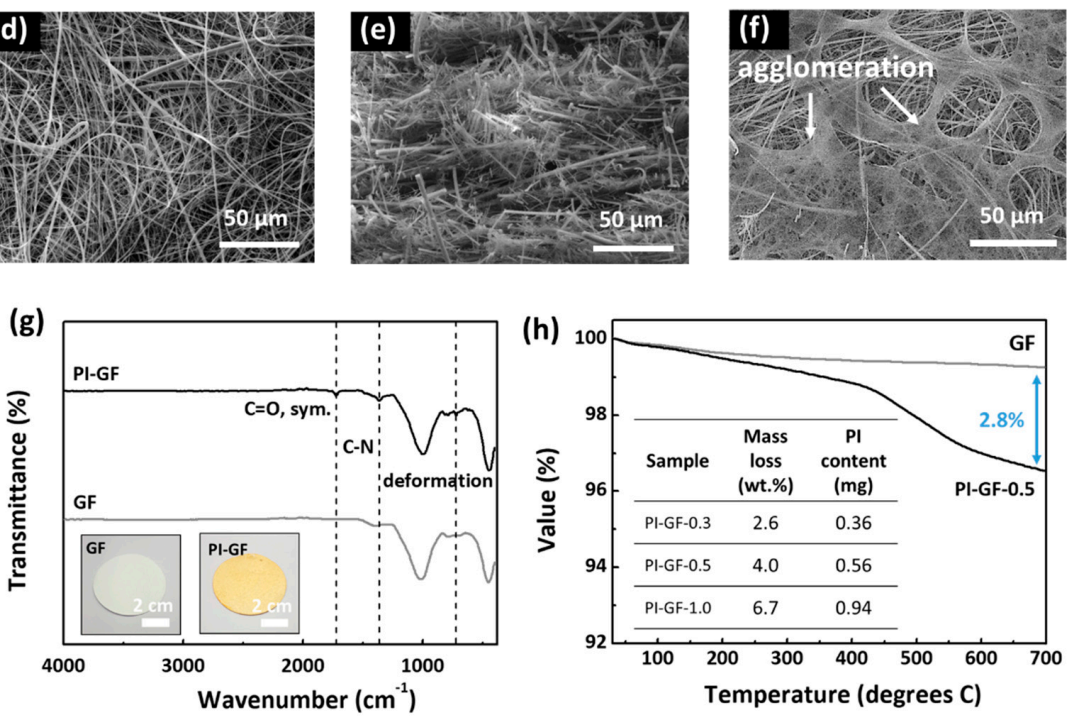

Figure 1. SEM images of (a) glass microfiber (GF); (b) polypropylene (PP); (c) the schematic diagram of the fabrication process for polyimide functionalized glass microfibers (PI-GF) separator and molecular structures of polyamic acid (PAA) salt and polyimide (PI); SEM images of (d,e) PI-GF-0.5 and (f) PI-GF-3 coated with organic (NMP) solutions; (g) Fourier transform infrared (FT-IR) spectra and (h) TGA curves of GF and PI-GF-0.5; (g, inset) photo images of GF and PI-GF; and (h, inset) mass loss and PI content in PI-GF- $x$. 
Before the electrochemical characterization of PI-GF- $x$ samples in LSB cells, we first assessed the adsorption capability of polysulfides by PI powders to see whether PI-GF- $x$ provided sufficient heterogeneous adsorption sites (or PI content) for polysulfides. PI powders (50, 100, and $150 \mathrm{mg}$ ) prepared under the same conditions except using GF were mixed with $25 \mathrm{mM} \mathrm{Li}_{2} \mathrm{~S}_{6}$ solution (1.6 mL) for $12 \mathrm{~h}$ under vigorous stirring in an Ar-filled glovebox until it reached equilibrium. Photo-images of the resulting supernatant showed that the catholyte solution of dark brown gradually become colorless with increasing the amount of PI powder and finally turned into a clear solution at $150 \mathrm{mg}$. Similarly, the absorption at both 350 and $450 \mathrm{~nm}$ assigned to $\mathrm{S}_{6}{ }^{2-}$ dissolved in DOL:DME (1:1, v/v) was substantially decreased with increasing PI powder in UV-Vis spectra of the supernatant [36-38]. With these results, it was roughly estimated that the adsorption capacity of PI powder for $\mathrm{Li}_{2} \mathrm{~S}_{6} \mathrm{Was}$ around $0.4 \mu \mathrm{mol} \mathrm{Li} \mathrm{L}_{6} / \mathrm{mg}$ PI. Assuming a sulphur utilization efficiency of $70 \%$ and complete dissolution of the remaining 30\% into the electrolyte at an areal sulphur loading of $2 \mathrm{mgS} / \mathrm{cm}^{2}$, we needed at least $12 \mathrm{mg}$ PI, which was an order of magnitude more than the PI content in PI-GF-1. Although this meant that all PI-GF- $x$ samples were obviously short of the surface adsorbents, it was very likely for the thin PI coating on GF to expose more carbonyl groups featuring high affinity to polysulfides as heterogeneous adsorption sites due to the nanostructure [39]. Indeed, it could be seen that the self-discharge of LSB cells at open-circuit voltage (OCV) was much reduced with PI-GF- $x$ samples as compared to that with the Celgard 2400 (Figure 2d,e). We noted from the stable OCV values with only GF that the surface silanol groups of borosilicate microfibers were also valid for polysulfides adsorption and thereby self-discharge protection, which was in good agreement with previous reports proving the efficient trapping of polysulfides in porous silica $[40,41]$. However, it was exceptional that the PI-GF-1.0 sample showed rather poor self-discharge protection ability than other samples, including the bare GF. As will be discussed later, the PI content in PI-GF of more than $1 \mathrm{mg}$ precluded ionic transfer especially in the presence of polysulfides. We thus limit our discussion to PI-GF- $x$ samples at $x \leq 1$.

(a)
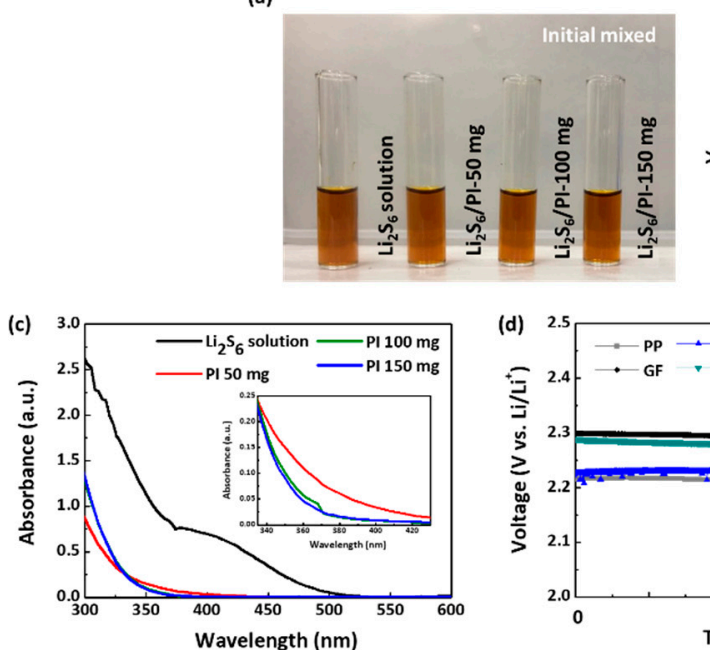

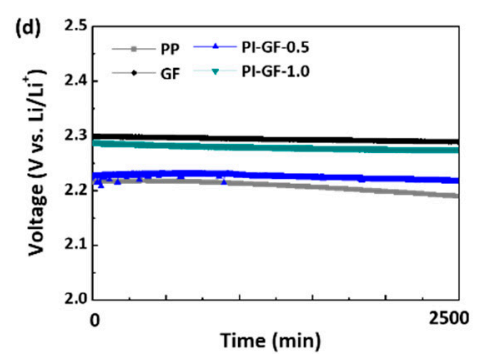

(b)
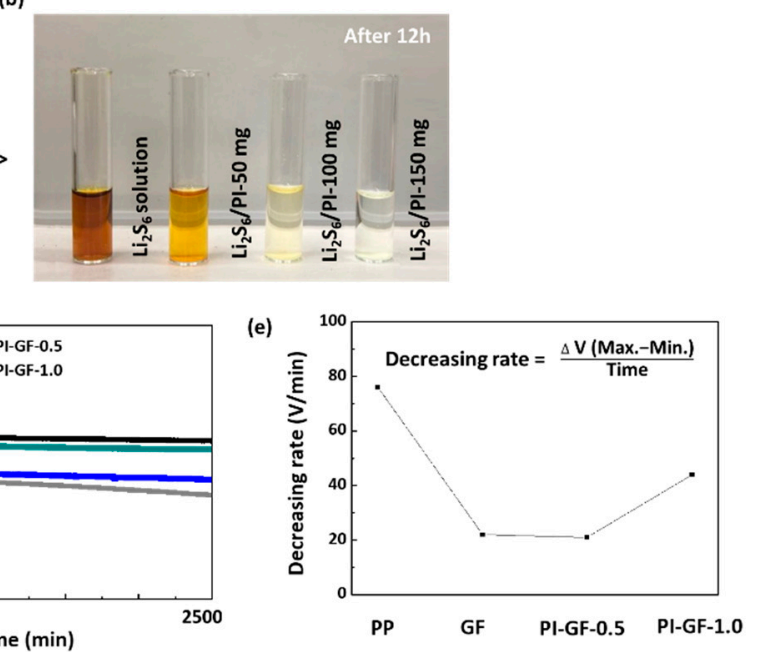

Figure 2. Adsorption test of polyimide powder in $25 \mathrm{mM} \mathrm{Li}_{2} \mathrm{~S}_{6}$ solution: Photo-images of the supernatant of solutions after (a) initial mixed and (b) $12 \mathrm{~h}$; (c) UV-vis spectra of the supernatant solutions; (d) self-discharge of lithium-sulphur batteries (LSBs) at open-circuit voltage (OCV); and (e) the corresponding decreasing rate.

Recently, we demonstrated that microporous carbon cloth (CC) with a small pore size of $1.2 \mathrm{~nm}$, a high surface area of $1630 \mathrm{~m}^{2} / \mathrm{g}$, and a high pore volume of $0.87 \mathrm{~cm}^{3} / \mathrm{g}$ was a decent sulphur-supporting material for high-performance, flexible LSBs [25]. Without using additional conductive additives, polymer binders, and porous supporting materials, the resulting LSB cells exhibited a specific capacity of 1100 and $548 \mathrm{mAh} / \mathrm{g}$ corresponding to a sulphur utilization efficiency of $66 \%$ and $33 \%$ at an areal sulphur loading of 2 and $6 \mathrm{mg} / \mathrm{cm}^{2}$, respectively, and $0.3 C$. In particular, a capacity loss of 0.137 and 
$0.129 \%$ per cycle was only marginal over 100 cycles due to the efficient physical trapping of polysulfides in micropores of $\sim 1.2 \mathrm{~nm}$. In the permanent presence of polysulfides of $\sim 34 \%$ in electrolyte, this was, however, enabled partly by sacrificial $\mathrm{LiNO}_{3}$ additive capable of passivating the surface of the $\mathrm{Li}$ metal anode. The problem here was that such a protective SEI layer based on $\mathrm{LiSO}_{\mathrm{x}}$ was temporary and would continuously degrade over cycles, eventually leading to cell failure [20,42]. It should be noted that most of the recent researches still rely on $\mathrm{LiNO}_{3}$ additives irrespective of their strategies. Additional trapping options for polysulfides are indispensable to avoid the same fate of LSB cells where it is important to minimize the detrimental effect of polysulfides shuttling on the Li metal anode if there is.

In order to investigate the effect of PI-GF- $x$ on the electrochemical performance of CC, galvanostatic cycling with potential limitation (GCPL) and electrochemical impedance spectroscopy (EIS) measurements were conducted at an areal sulphur loading of $2 \mathrm{mgS} / \mathrm{cm}^{2}$ and an areal current density of $1.0 \mathrm{~mA} / \mathrm{cm}^{2}$, corresponding to $0.3 \mathrm{C}$, in the potential range between 1.8 and $2.6 \mathrm{~V} \mathrm{vs}$. $\mathrm{Li} / \mathrm{Li}^{+}$. The E/S ratio was set to be $\sim 60$ by using $1 \mathrm{M} \mathrm{Li}_{2} \mathrm{~S}_{6}$ catholyte solution as a sulphur source, under which condition the electrolyte was considered a dilute solution. The low concentration gradient made it difficult for PI-GF- $x$ to drive surface adsorption of polysulfides toward equilibrium. We also used the tough condition to exaggerate the polysulfide shuttling in LSB cells as the dilute electrolyte drove more dissolution of polysulfides from the cathode. These cells were rested at OCV for $12 \mathrm{~h}$ before the GCPL test to drive self-discharge reaction if there was any, and then first charged to the upper potential limit in order to electrochemically infiltrate sulphur into CC. The first charge curve was removed from the GCPL profiles in order to avoid confusion unless otherwise noted.

Figure 3a shows a capacity vs. cycle number graph of PI-GF- $x$ samples. It is clear that PI-GF-0.5 outperformed other samples including GF in terms of capacity generation and cycle stability; PI-GF-0.5 generated a maximum capacity of $1328 \mathrm{mAh} / \mathrm{g}$ corresponding to a sulphur utilization efficiency of $79.5 \%$ with a high Coulombic efficiency of $99.12 \%$ and a marginal capacity loss of $0.099 \% / c y c l e$ over 120 cycles, while other samples showed a lower capacity generation by $10 \%$ and suffered from a sudden cell failure in 60-70 cycles. The CC cathode combined with PI-GF-0.5, as expected, still performed in the same manner as with the Celgard 2400 or GF (Figure 3b). The GCPL profiles of PI-GF-0.5 showed two typical plateaus at 2.3 and $2.0 \mathrm{~V} \mathrm{vs.} \mathrm{Li} / \mathrm{Li}^{+} \mathrm{during}$ discharge corresponding to reduction reactions of sulphur to high $\left(\mathrm{Li}_{2} \mathrm{~S}_{x}, 4 \leq x \leq 8\right)$ and low $\left(\mathrm{Li}_{2} \mathrm{~S}_{x}\right.$, $1 \leq x<4$ ) polysulfides/lithium sulfide, respectively, followed by a gradually sloping charge profile toward the upper potential limit attributed to the subsequent oxidation reactions of lithium sulfide, and polysulfides to elemental sulphur [25]. For PI-GF-0.5, the capacity ratio of low (700-800 mAh/g) to high $(550 \mathrm{mAh} / \mathrm{g})$ polysulfides remained at $\sim 1.45$, which was much lower than the theoretical value (3). We attributed this to the microporous CC which is efficient at reactions of soluble high polysulfides responsible for shuttling, but poor at those of insoluble low polysulfides causing pore-blockage [25,43]. The PI-GF-0.5 contributed mainly to the improvement in the former by retarding polysulfides shuttling and thereby keeping the high polysulfides in close proximity to the reaction sites on CC, which was probably why PI-GF-0.5 showed no sign of shuttling during charge, i.e., charge profile drooping or fluctuation without reaching the upper potential limit. We do not exclude the fact that PI is an electrochemically active material for lithium ions in the potential range between 1.9 and $2.3 \mathrm{~V} \mathrm{vs}$. $\mathrm{Li} / \mathrm{Li}^{+}$ well-enveloped in the lower and upper potential limit of GCPL measurement either [39]. It is, however, not only almost impossible to precisely determine the mass of PI taking part in the electrochemical reaction, but also highly unlikely that such a reaction consistently happens at a remote mode without establishing intimate contact with the current collector. 
(a)

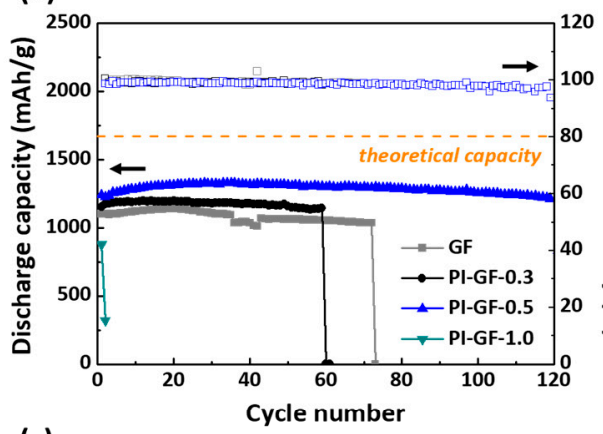

(c)
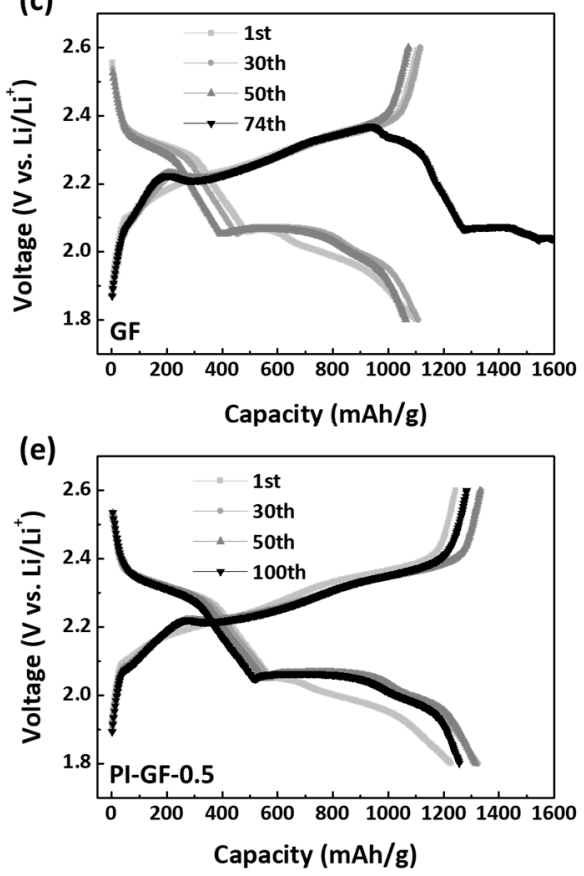

(b)

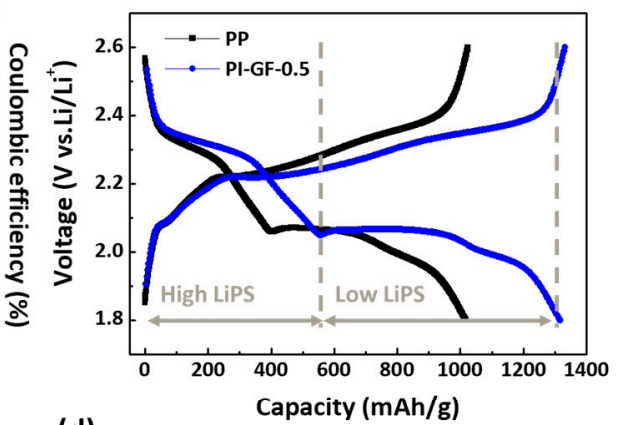

(d)
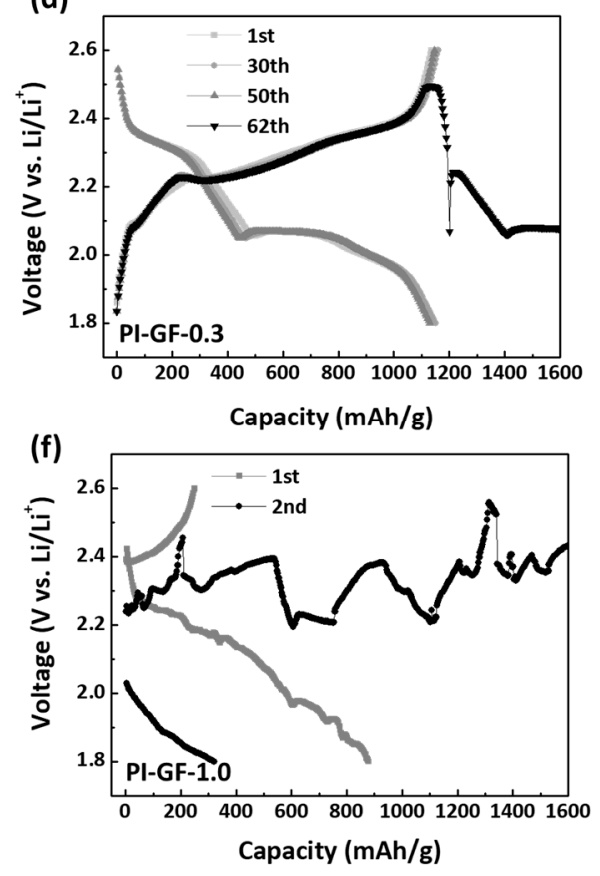

Figure 3. (a) Comparison of electrochemical performance depending on separators at $2 \mathrm{mgS} / \mathrm{cm}^{2}$ and 0.3C. (b-f) Charge/discharge profiles of different separators: (b) PP, (c) GF, (d) PI-GF-0.3, (e) PI-GF-0.5, and (f) PI-GF-1.0.

The role of PI-GF-0.5 in improving the electrochemical performance of LSB cells was investigated in more detail. It is well-known that polar polymers containing oxygen or nitrogen atoms in polymeric separators such as polyacrylonitrile, poly(methyl methacrylate) facilitate the lithium-ion transfer and distribution and thereby improves the performance of lithium metal anode in carbonate-based electrolyte due to their high affinity [44]. We assumed that the same is true for PI in ether-based electrolytes. Pyridinic nitrogen atoms in PI, which act as lithiophilic sites, has been reported to regulate the cation pathway and their nucleation [45]. Also, it is expected to reduce the overpotential required for lithium plating/stripping. Superior cycle stability and rate capability of PI-GF-0.5 to GF in lithium plating/stripping reactions using 1M LiTFSI solution dissolved in DOL:DME (1:1, v/v) were confirmed. During the cycle stability test of $1700 \mathrm{~h}$ (500 cycles) at a constant current density of $0.35 \mathrm{~mA} / \mathrm{cm}^{2}$, the overpotential remained as low as $5 \mathrm{mV}$ except for the initial fluctuation in PI-GF-0.5 during conditioning (Figure 4a). In the following rate capability test, the overpotential only slightly increased by $0.3 \mathrm{mV}$ with increasing current density from 0.35 to $2.8 \mathrm{~mA} / \mathrm{cm}^{2}$ and again remained stable even at $2.8 \mathrm{~mA} / \mathrm{cm}^{2}$ (Figure $4 \mathrm{~b}$ ). 
(a)

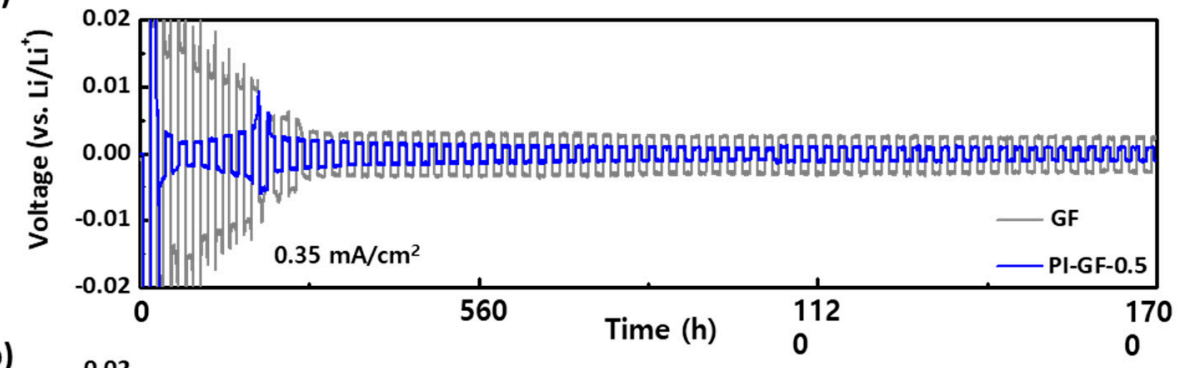

(b)

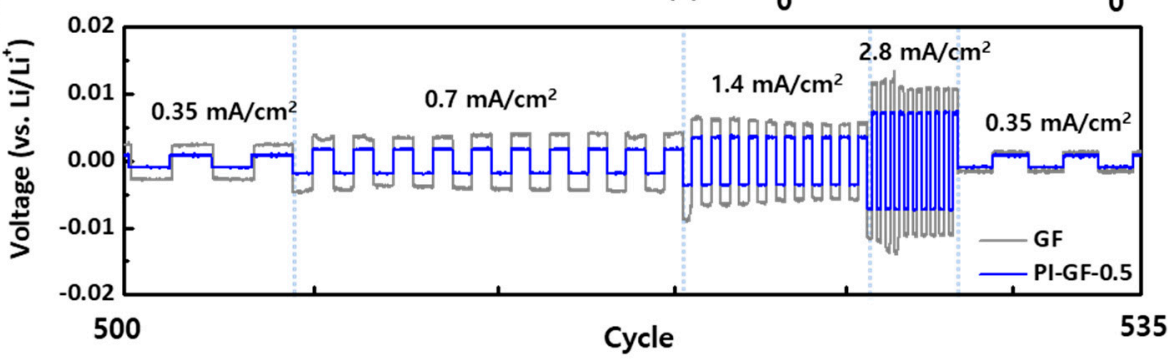

(c)

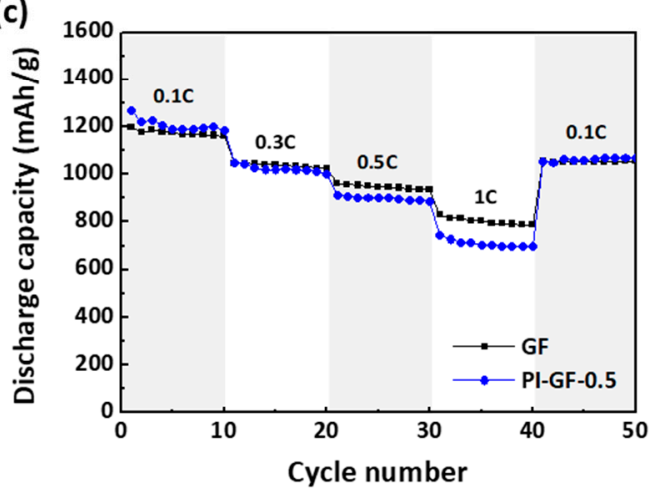

(d)

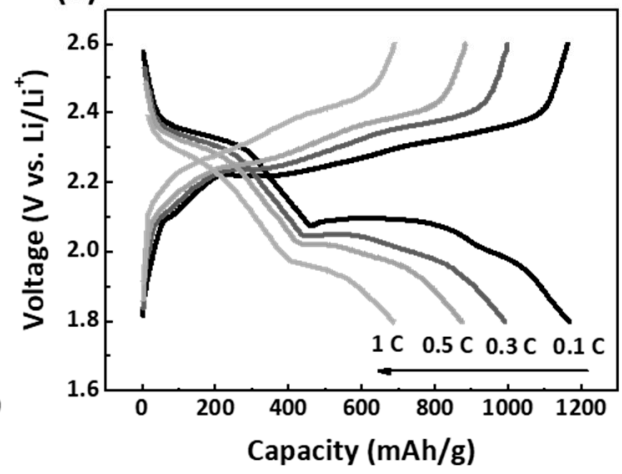

Figure 4. (a) Lithium stripping/plating performance in $\mathrm{Li} / \mathrm{Li}$ symmetric cells with $\mathrm{GF}$ and PI-GF-0.5 separators: (a) cycle stability of $1700 \mathrm{~h}$ ( 500 cycles) at a constant current density of $0.35 \mathrm{~mA} / \mathrm{cm}^{2}$ and (b) rate capability in the current density from 0.35 to $2.8 \mathrm{~mA} / \mathrm{cm}^{2}$. (c) Rate capability performance of LSBs using the GF and PI-GF-0.5 separators at $2 \mathrm{mgS} / \mathrm{cm}^{2}$, (d) the corresponding charge/discharge profile of PI-GF-0.5.

Despite the superior performance of the lithium metal anode, PI-GF-0.5-based LSB cells showed a slightly lower rate capability than those of GF-based ones. This means that the polysulfides adsorption affected the lithium-ion transfer through PI-GF-0.5 [46] (Figure 4c,d). In order to clarify the effect of polysulfide adsorption on the ionic conductivity of PI-GF-0.5, EIS measurement was conducted using $\mathrm{Al} /$ separator-electrolyte/Al symmetric cells. The ionic conductivity $(\sigma)$ was calculated as follows:

$$
\sigma=\frac{d}{R_{b} A},
$$

where $d$ is the thickness of the separator, $R_{b}$ is the intersection of the Nyquist plot with the Z-axis at the highest frequency, indicating the bulk electrolyte resistance, and $A$ is the contact area between electrode and separator $[47,48]$. In the absence of the polysulfides, the ionic conductivity of PI-GF- $x$ samples gradually increased with increasing the PI content, even 1.36 times higher than that of GF, matching well with the results of lithium plating/stripping reactions (Figure 5a,b). On the contrary, the ionic conductivity decreased with the PI content in the presence of polysulfides. The effect was especially pronounced at $x=1$, where the high content of polysulfide-philic PI allowed adsorption of polysulfides to a large extent, substantially reducing the ionic conductivity and thus leading to sudden LSB cell failure of PI-GF-1. The same interpretation applies to the initial bulk cell resistance 
of PI-GF- $x$-based LSBs at an areal sulphur loading of $2 \mathrm{mgS} / \mathrm{cm}^{2}$ (Figure $5 \mathrm{c}$ ). For example, the bulk resistance and charge transfer resistance noticeably increased for PI-GF-1 due to the high loading of polysulfides on its surface.
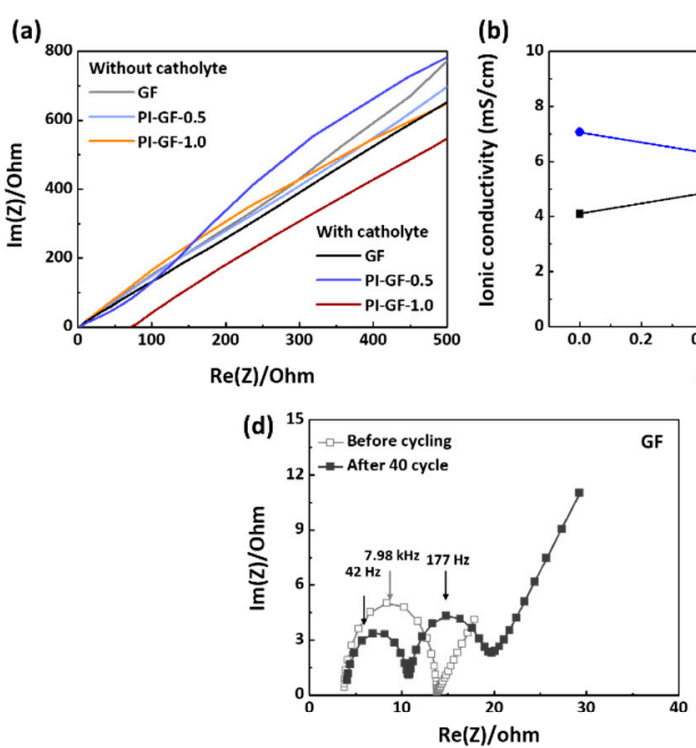

(f)

\begin{tabular}{ccccccc}
\hline & $\mathbf{R}_{\mathrm{b}}\left[\boldsymbol{\Omega} \cdot \mathrm{cm}^{2}\right]$ & $\mathbf{R}_{\text {int }}\left[\Omega \cdot \mathrm{cm}^{2}\right]$ & $\mathbf{R}_{\mathrm{ct}}\left[\Omega \cdot \mathrm{cm}^{2}\right]$ & Warburg $\left[\Omega^{0.5]} \begin{array}{c}\text { Capacitance_ } \\
1[\mathrm{~F}]\end{array} \begin{array}{c}\text { Capacitance } \\
\mathbf{2}[\mathrm{F}]\end{array}\right.$ \\
\hline GF_Before & 1.78 & 12.76 & 0 & 1.40 & 0 & 0.23 \\
\hline GF_After 40 cycle & 2.82 & 15.17 & 3.59 & 14.10 & $29.87 \mathrm{e}^{-6}$ & $1.05 \mathrm{e}^{-3}$ \\
\hline PI-GF-0.5_Before & 3.20 & 9.46 & 1.10 & 3.04 & $16.64 \mathrm{e}^{-6}$ & 0.11 \\
\hline PI-GF-0.5_After 40 cycle & 2.97 & 3.65 & 6.01 & 4.23 & $0.11 \mathrm{e}^{-3}$ & 0.11 \\
\hline
\end{tabular}
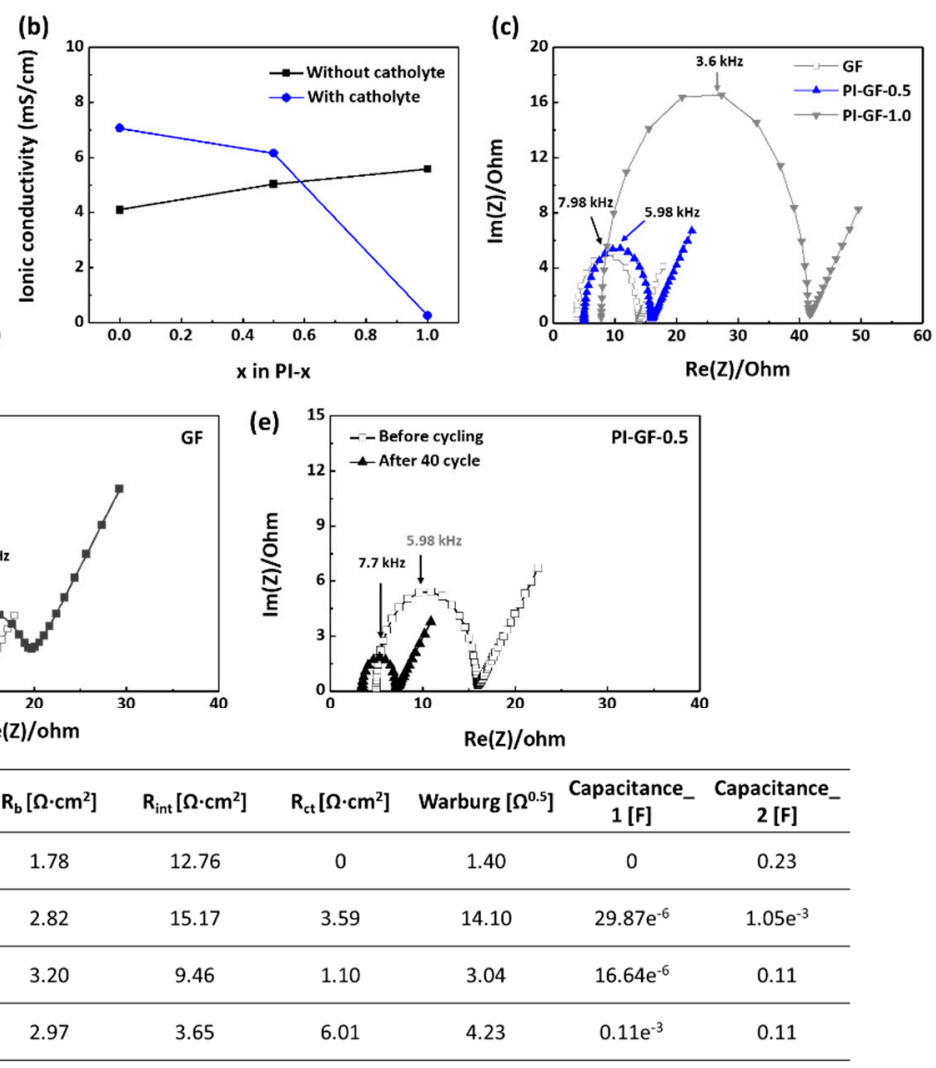

Figure 5. (a) Electrochemical impedance spectroscopy (EIS) Nyquist plot for Al/separator-electrolyte/Al symmetric cells and (b) corresponding ionic conductivity without and with $1 \mathrm{M} \mathrm{Li}_{2} \mathrm{~S}_{6}$ solution, (c-e) EIS Nyquist plot for LSBs under the GF, PI-0.5, and PI-1 separators before and after cycling, and (f) corresponding fitted capacitance and resistance values.

Photo and SEM images of the cycled electrodes and separators help us roughly qualify/quantify and visualize the mode of surface adsorption of polysulfides. The LSB cells using GF, PI-GF-0.5, and PI-GF-1 were disassembled after charge/discharge cycles at an areal sulphur loading of $2 \mathrm{mgS} / \mathrm{cm}^{2}$ and their changes in surface morphology, texture, and color were observed. Judging from the color change of the cycled separator samples, the polysulfide shuttling clearly happened in LSBs cells even at such low areal sulphur loading (Figure 6a-c). We assume from the utilization efficiency in GCPL experiments that around $20-30 \%$ of total sulphur added was dissolved into the electrolyte solution. GF and PI-GF- $x$ turned yellow and green with polysulfides, respectively, where the latter agreed well with what has been seen in previous reports [49]. It was found in photo images of PI-GF- $x$ that the higher the PI content, the darker the green. Similarly, we found from SEM images that the formation of particles and thin coating layers in PI-GF- $x$ got more significant with increasing PI content. The particles filled the voids between the fibers of GF. In addition, the thin coating layers of polysulfides were created at the corner and completely covered the space by cohesive forces [50]. This is probably why the ionic conductivity of PI-GF-1-based LSB cells significantly reduced. 

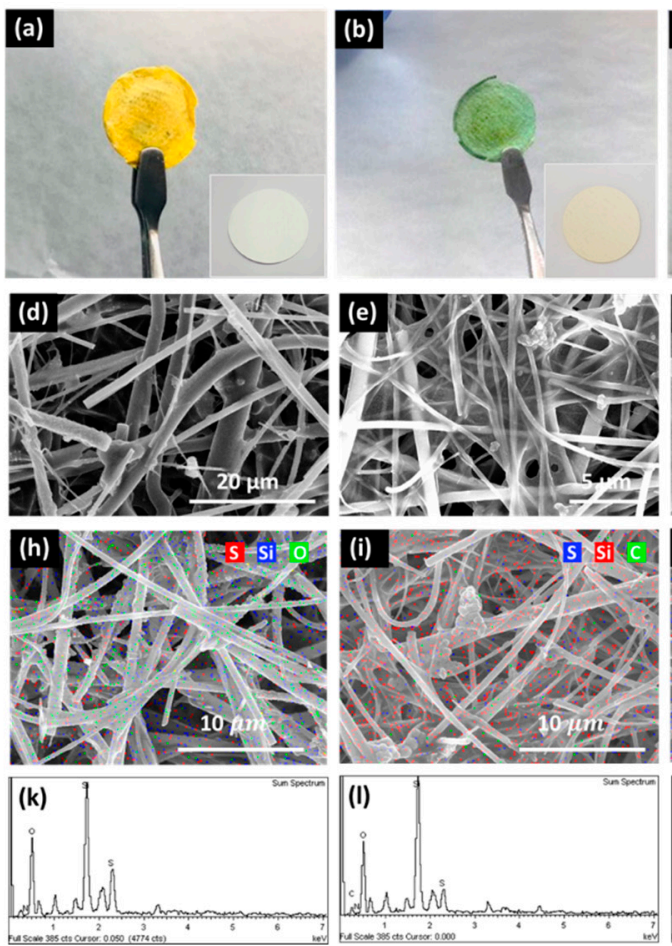
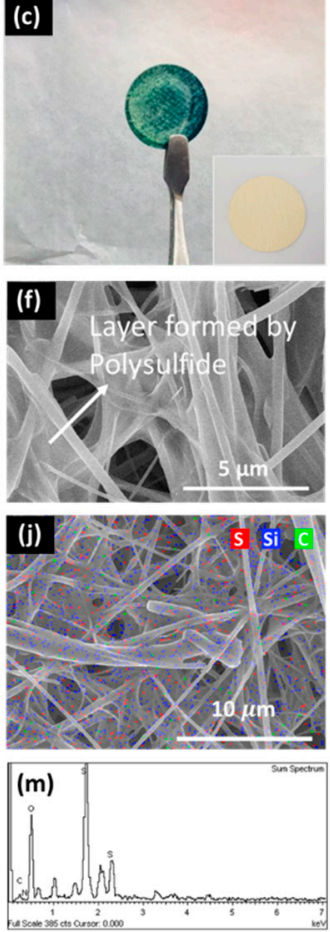

(g)

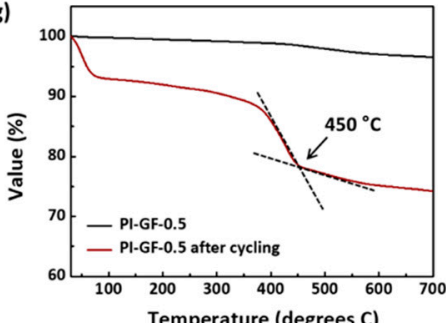

\begin{tabular}{cccc}
\hline Element & GF & Pl-GF-0.5 & Pl-GF-1.0 \\
\hline $\mathrm{C}[w t . \%]$ & - & 12.46 & 8.89 \\
\hline $\mathrm{N}[\mathrm{wt} \%$ \%] & 4.46 & 9.44 & 8.92 \\
\hline $\mathrm{O}[\mathrm{wt} \%$ \%] & 53.27 & 47.15 & 49.21 \\
\hline Si [wt. \%] & 27.48 & 24.99 & 23.64 \\
\hline $\mathrm{S}[\mathrm{wt} . \%]$ & 14.79 & 5.96 & 5.22 \\
\hline
\end{tabular}

Figure 6. (a-c) Photo images and (d-f) SEM images: (a,d) GF, (b,e) PI-0.5, and (c,f) PI-1 separators after cycling, (a-c, inset) separators before cycling. (g) TGA curves of PI-GF-0.5 before and after cycling, $(\mathbf{h}-\mathbf{n})$ EDS mapping and analysis: $(\mathbf{h}, \mathbf{k})$ GF, $(\mathbf{i}, \mathbf{l})$ PI-GF-0.5, $(\mathbf{j}, \mathbf{m})$ PI-GF-1.0, and (n) EDS element analysis of separators.

TGA results of the cycled PI-GF- 0.5 show that the weight loss of about $7 \%$ and $12 \%$ was centered at around $100{ }^{\circ} \mathrm{C}$ and $450{ }^{\circ} \mathrm{C}$, respectively. The latter is mainly attributed to the adsorbed polysulfide in PI-GF-0.5. Given that sublimation of elemental sulphur occurs mainly at $<300{ }^{\circ} \mathrm{C}$, high evaporation temperature suggests that polysulfides bind strongly to PI-GF-0.5 [51]. EDS mapping and quantification results reveal that sulphur species were indeed well-distributed in the separator samples after DME washing. The PI-GF- 0.5 contained about $10 \%$ less sulphur content compared to GF, probably indicating that the thin polysulfide layers created between fibers prevented the dissolved polysulfide from penetrating deep into the PI-GF-0.5.

\section{Conclusions}

To conclude, we demonstrated a synergistic combination of porous carbon cloth (CC) with a polyimide coated glass microfiber (PI-GF) for high-performance LSBs. CC and PI-GF function as a sulphur-supporting material and a polysulfide perm-selective separator, respectively, in which PI-GF helps polysulfides kept in close proximity to the CC by forming polysulfide films supported by microfibers via cohesive force. The degree of film formation is determined by the content of PI around $0.5 \mathrm{wt} \%$, which requires delicate control. This was enabled by the aqueous PAA-solution-based synthesis of homogeneous thin PI coating on GF with the potential to scale and fine-tune. As a result, CC combined with PI-GF exhibited a sulphur utilization efficiency of $79.5 \%$ with a marginal capacity loss of $0.099 \% /$ cycle over 120 cycles.

Author Contributions: Conceptualization, Y.-S.J. and Y.H.K.; investigation, M.-J.K., H.J.H., H.-J.K., and K.Y.; writing—original draft preparation, M.-J.K. and K.Y.; writing—review and editing, Y.-S.J., Y.H.K., and J.C.W.

Funding: This research received no external funding.

Acknowledgments: This work was financially supported by the R\&D Convergence Program of NST (National Research Council of Science \& Technology) of Republic of Korea (CAP-15-02-KBSI), the National Research Foundation of Korea (NRF) grant funded by the Korea government (MSIT)(No. 2019R1C1C1007745), the National 
Research Foundation of Korea (NRF) grant funded by the Korea government (Ministry of Science, ICT \& Future Planning) (No. 2019R1A4A2001527), the Center for Advanced Soft-Electronics funded by the Ministry of Science, ICT as Global Frontier Project (CASE-2015M3A6A5065315) and KRICT core project (SI1921-20).

Conflicts of Interest: The authors declare no conflict of interest.

\section{References}

1. Suberu, M.Y.; Mustafa, M.W.; Bashir, N. Energy storage systems for renewable energy power sector integration and mitigation of intermittency. Renew. Sustain. Energy Rev. 2014, 35, 499-514. [CrossRef]

2. Panwar, N.L.; Kaushik, S.C.; Kothari, S. Role of renewable energy sources in environmental protection: A review. Renew. Sustain. Energy Rev. 2011, 15, 1513-1524. [CrossRef]

3. Divya, K.C.; Ostergaard, J. Battery energy storage technology for power systems-An overview. Electr. Power Syst. Res. 2009, 79, 511-520. [CrossRef]

4. Koppelaar, R.H.E.M.; Keirstead, J.; Shah, N.; Woods, J. A review of policy analysis purpose and capabilities of electricity system models. Renew. Sustain. Energy Rev. 2016, 59, 1531-1544. [CrossRef]

5. Tarascon, J.M.; Armand, M. Issues and challenges facing rechargeable lithium batteries. Nature 2001, 414, 359-367. [CrossRef]

6. Reddy, M.V.; Rao, G.V.S.; Chowdari, B.V.R. Metal Oxides and Oxysalts as Anode Materials for Li Ion Batteries. Chem. Rev. 2013, 113, 5364-5457. [CrossRef]

7. Xiulei, J.; Kyu Tae, L.; Nazar, L.F. A highly ordered nanostructured carbon-sulphur cathode for lithium-sulphur batteries. Nat. Mater. 2009, 500-506.

8. Cunningh, P.T.; Cairns, E.J.; Johnson, S.A. Phase Equilibria in Lithium-Chalcogen Systems II. Lithium-Sulfur. J. Electrochem. Soc. 1972, 119, 1448-1450. [CrossRef]

9. Worthington, M.J.H.; Kucera, R.L.; Chalker, J.M. Green chemistry and polymers made from sulfur. Green Chem. 2017, 19, 2748-2761. [CrossRef]

10. Jiulin, W.; Jun, Y.; Chunrong, W.; Ke, D.; Jingying, X.; Naixin, X. Sulfur composite cathode materials for rechargeable lithium batteries. Adv. Funct. Mater. 2003, 13, 487-492.

11. Hagen, M.; Hanselmann, D.; Ahlbrecht, K.; Maca, R.; Gerber, D.; Tubke, J. Lithium-Sulfur Cells: The Gap between the State-of-the-Art and the Requirements for High Energy Battery Cells. Adv. Energy Mater. 2015, 5, 1401986. [CrossRef]

12. Liang, C.D.; Dudney, N.J.; Howe, J.Y. Hierarchically Structured Sulfur/Carbon Nanocomposite Material for High-Energy Lithium Battery. Chem. Mater. 2009, 21, 4724-4730. [CrossRef]

13. Yang, Y.; Yu, G.H.; Cha, J.J.; Wu, H.; Vosgueritchian, M.; Yao, Y.; Bao, Z.A.; Cui, Y. Improving the Performance of Lithium-Sulfur Batteries by Conductive Polymer Coating. ACS Nano 2011, 5, 9187-9193. [CrossRef]

14. Wang, H.; Yang, Y.; Liang, Y.; Robinson, J.T.; Li, Y.; Jackson, A.; Cui, Y.; Dai, H. Graphene-Wrapped Sulfur Particles as a Rechargeable Lithium-Sulfur Battery Cathode Material with High Capacity and Cycling Stability. Nano Lett. 2011, 11, 2644-2647. [CrossRef]

15. Li, D.; Han, F.; Wang, S.; Cheng, F.; Sun, Q.; Li, W.-C. High Sulfur Loading Cathodes Fabricated Using Peapodlike, Large Pore Volume Mesoporous Carbon for Lithium-Sulfur Battery. ACS Appl. Mater. Interfaces 2013, 5, 2208-2213. [CrossRef]

16. Hassoun, J.; Scrosati, B. Moving to a Solid-State Configuration: A Valid Approach to Making Lithium-Sulfur Batteries Viable for Practical Applications. Adv. Mater. 2010, 22, 5198-5201. [CrossRef]

17. Zhang, S.; Ueno, K.; Dokko, K.; Watanabe, M. Recent Advances in Electrolytes for Lithium-Sulfur Batteries. Adv. Energy Mater. 2015, 5, 1500117. [CrossRef]

18. Seh, Z.W.; Zhang, Q.F.; Li, W.Y.; Zheng, G.Y.; Yao, H.B.; Cui, Y. Stable cycling of lithium sulfide cathodes through strong affinity with a bifunctional binder. Chem. Sci. 2013, 4, 3673-3677. [CrossRef]

19. Liu, M.; Ren, Y.X.; Zhou, D.; Jiang, H.R.; Kang, F.Y.; Zhao, T. A Lithium/Polysulfide Battery with Dual-Working Mode Enabled by Liquid Fuel and Acrylate-Based Gel Polymer Electrolyte. ACS Appl. Mater. Interfaces 2017, 9, 2526-2534. [CrossRef]

20. Yang, Y.; Zheng, G.Y.; Cui, Y. A membrane-free lithium/polysulfide semi-liquid battery for large-scale energy storage. Energy Environ. Sci. 2013, 6, 1552-1558. [CrossRef]

21. Green, J. The Flame Retardation of Polyolefins. In Flame-Retardant Polymeric Materials; Lewin, M., Atlas, S.M., Pearce, E.M., Eds.; Springer: New York, NY, USA; Boston, MA, USA, 1982; Volume 3, pp. 1-37. 
22. Yu, L.; Miao, J.; Jin, Y.; Lin, J.Y.S. A comparative study on polypropylene separators coated with different inorganic materials for lithium-ion batteries. Front. Chem. Sci. Eng. 2017, 11, 346-352. [CrossRef]

23. Famprikis, T.; Canepa, P.; Dawson, J.A.; Islam, M.S.; Masquelier, C. Fundamentals of inorganic solid-state electrolytes for batteries. Nat. Mater. 2019. [CrossRef]

24. Umeshbabu, E.; Zheng, B.; Yang, Y. Recent Progress in All-Solid-State Lithium-Sulfur Batteries Using High Li-Ion Conductive Solid Electrolytes. Electrochem. Energy Rev. 2019, 2, 199-230. [CrossRef]

25. Song, J.-Y.; Lee, H.-H.; Hong, W.; Huh, Y.; Lee, Y.; Kim, H.; Jun, Y.-S. A Polysulfide-Infiltrated Carbon Cloth Cathode for High-Performance Flexible Lithium-Sulfur Batteries. Nanomaterials 2018, 8, 90. [CrossRef]

26. Kirchhöfer, M.; Von Zamory, J.; Paillard, E.; Passerini, S. Separators for Li-Ion and Li-Metal Battery Including Ionic Liquid Based Electrolytes Based on the TFSI- and FSI- Anions. Int. J. Mol. Sci. 2014, 15, 14868-14890. [CrossRef]

27. Yang, J.; Lee, M.H. A water-soluble polyimide precursor: Synthesis and characterization of poly (amic acid) salt. Macroml. Res. 2004, 12, 263-268. [CrossRef]

28. Sun, G.H.; Dong, G.Q.; Kong, L.S.; Yan, X.N.; Tian, G.F.; Qi, S.L.; Wu, D.Z. Robust polyimide nanofibrous membrane with porous-layer-coated morphology by in situ self-bonding and micro-crosslinking for lithium-ion battery separator. Nanoscale 2018, 10, 22439-22447. [CrossRef]

29. Jun, Y.S.; Hong, W.H.; Antonietti, M.; Thomas, A. Mesoporous, 2D Hexagonal Carbon Nitride and Titanium Nitride/Carbon Composites. Adv. Mater. 2009, 21, 4270-4274. [CrossRef]

30. Chen, X.F.; Jun, Y.S.; Takanabe, K.; Maeda, K.; Domen, K.; Fu, X.Z.; Antonietti, M.; Wang, X.C. Ordered Mesoporous SBA-15 Type Graphitic Carbon Nitride: A Semiconductor Host Structure for Photocatalytic Hydrogen Evolution with Visible Light. Chem. Mater. 2009, 21, 4093-4095. [CrossRef]

31. Yang, S.-Y.; Yuan, L.-L. Chapter 1-Advanced Polyimide Films. In Advanced Polyimide Materials; Yang, S.-Y., Ed.; Elsevier: Amsterdam, The Netherlands, 2018; pp. 1-66.

32. Wang, L.; Deng, N.P.; Fan, L.L.; Wang, L.Y.; Wang, G.; Kang, W.M.; Cheng, B.W. A novel hot-pressed electrospun polyimide separator for lithium-sulfur batteries. Mater. Lett. 2018, 233, 224-227. [CrossRef]

33. Li, J.; Luo, K.J.; Yu, J.R.; Wang, Y.; Zhu, J.; Hu, Z.M. Promising Free-Standing Polyimide Membrane via Solution Blow Spinning for High Performance Lithium-Ion Batteries. Ind. Eng. Chem. Res. 2018, 57, 12296-12305. [CrossRef]

34. Xiu, T.P.; Liu, Q.; Wang, J.C. Alkali-free borosilicate glasses with wormhole-like mesopores. J. Mater. Chem. 2006, 16, 4022-4024. [CrossRef]

35. Wang, J.C.; Liu, Q. Mesoporous silicon oxynitride thin films. Chem. Commun. 2006, 8, 900-902. [CrossRef] [PubMed]

36. Wu, D.S.; Shi, F.; Zhou, G.; Zu, C.; Liu, C.; Liu, K.; Liu, Y.; Wang, J.; Peng, Y.; Cui, Y. Quantitative investigation of polysulfide adsorption capability of candidate materials for Li-S batteries. Energy Storage Mater. 2018, 13, 241-246. [CrossRef]

37. Xia, Y.; Fang, R.; Xiao, Z.; Huang, H.; Gan, Y.; Yan, R.; Lu, X.; Liang, C.; Zhang, J.; Tao, X.; et al. Confining Sulfur in N-Doped Porous Carbon Microspheres Derived from Microalgaes for Advanced Lithium-Sulfur Batteries. ACS Appl. Mater. Interfaces 2017, 9, 23782-23791. [CrossRef] [PubMed]

38. Zou, Q.L.; Lu, Y.C. Solvent-Dictated Lithium Sulfur Redox Reactions: An Operando UV-vis Spectroscopic Study. J. Phys. Chem. Lett. 2016, 7, 1518-1525. [CrossRef]

39. Wu, H.P.; Yang, Q.; Meng, Q.H.; Ahmad, A.; Zhang, M.; Zhu, L.Y.; Liu, Y.G.; Wei, Z.X. A polyimide derivative containing different carbonyl groups for flexible lithium ion batteries. J. Mater. Chem. A 2016, 4, 2115-2121. [CrossRef]

40. Ji, X.L.; Evers, S.; Black, R.; Nazar, L.F. Stabilizing lithium-sulphur cathodes using polysulphide reservoirs. Nat. Commun. 2011, 2, 325. [CrossRef]

41. Demir-Cakan, R.; Morcrette, M.; Nouar, F.; Davoisne, C.; Devic, T.; Gonbeau, D.; Dominko, R.; Serre, C.; Ferey, G.; Tarascon, J.M. Cathode Composites for Li-S Batteries via the Use of Oxygenated Porous Architectures. J. Am. Chem. Soc. 2011, 133, 16154-16160. [CrossRef]

42. Sahore, R.; Levin, B.D.A.; Pan, M.; Muller, D.A.; DiSalvo, F.J.; Giannelis, E.P. Design Principles for Optimum Performance of Porous Carbons in Lithium-Sulfur Batteries. Adv. Energy Mater. 2016, 6, 1600134. [CrossRef]

43. Zheng, S.Y.; Yi, F.; Li, Z.P.; Zhu, Y.J.; Xu, Y.H.; Luo, C.; Yang, J.H.; Wang, C.S. Copper-Stabilized Sulfur-Microporous Carbon Cathodes for Li-S Batteries. Adv. Funct. Mater. 2014, 24, 4156-4163. [CrossRef] 
44. Lee, H.; Yanilmaz, M.; Toprakci, O.; Fu, K.; Zhang, X. A review of recent developments in membrane separators for rechargeable lithium-ion batteries. Energy Environ. Sci. 2014, 7, 3857-3886. [CrossRef]

45. Zhang, R.; Chen, X.-R.; Chen, X.; Cheng, X.-B.; Zhang, X.-Q.; Yan, C.; Zhang, Q. Lithiophilic Sites in Doped Graphene Guide Uniform Lithium Nucleation for Dendrite-Free Lithium Metal Anodes. Angew. Chem. Int. Ed. 2017, 56, 7764-7768. [CrossRef] [PubMed]

46. Kalantarian, M.M.; Asgari, S.; Mustarelli, P. A theoretical approach to evaluate the rate capability of Li-ion battery cathode materials. J. Mater. Chem. A 2014, 2, 107-115. [CrossRef]

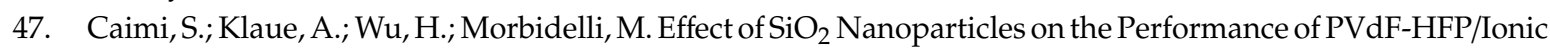
Liquid Separator for Lithium-Ion Batteries. Nanomaterials 2018, 8, 926. [CrossRef] [PubMed]

48. Kong, L.; Fu, X.; Fan, X.; Wang, Y.; Qi, S.; Wu, D.; Tian, G.; Zhong, W.-H. A Janus nanofiber-based separator for trapping polysulfides and facilitating ion-transport in lithium-sulfur batteries. Nanoscale 2019, 11, 18090-18098. [CrossRef]

49. Wang, Y.; Zhang, Z.; Haibara, M.; Sun, D.; Ma, X.; Jin, Y.; Munakata, H.; Kanamura, K. Reduced Polysulfide Shuttle Effect by Using Polyimide Separators with Ionic Liquid-based Electrolytes in Lithium-Sulfur Battery. Electrochim. Acta 2017, 255, 109-117. [CrossRef]

50. Yun, J.H.; Kim, J.-H.; Kim, D.K.; Lee, H.-W. Suppressing Polysulfide Dissolution via Cohesive Forces by Interwoven Carbon Nanofibers for High-Areal-Capacity Lithium-Sulfur Batteries. Nano Lett. 2018, 18, 475-481. [CrossRef]

51. Zheng, M.; Hu, Q.; Zhang, S.; Tang, H.; Li, L.; Pang, H. Macroporous Activated Carbon Derived from Rapeseed Shell for Lithium-Sulfur Batteries. Appl. Sci. 2017, 7, 1036. [CrossRef]

(C) 2019 by the authors. Licensee MDPI, Basel, Switzerland. This article is an open access article distributed under the terms and conditions of the Creative Commons Attribution (CC BY) license (http://creativecommons.org/licenses/by/4.0/). 